\title{
Survival analysis of elderly patients over 65 years old with stage II/III gastric cancer treated with adjuvant chemotherapy after laparoscopic D2 gastrectomy: a retrospective cohort study
}

\author{
Yanrui Liang ${ }^{*}{ }^{\dagger}$, Liying Zhao ${ }^{\dagger}$, Hao Chen ${ }^{\dagger}$, Tian Lin, Tao Chen, Mingli Zhao, Yanfeng Hu, Jiang Yu, Hao Liu and
} Guoxin Li

\begin{abstract}
Background: The benefits of adjuvant chemotherapy for elderly patients with gastric cancer (GC) remain unknown because elderly patients are underrepresented in most clinical trials. This study aimed to evaluate the effectiveness and complications of adjuvant chemotherapy in patients $>65$ years of age after laparoscopic D2 gastrectomy.

Methods: This was a single-center retrospective cohort study of elderly patients (> 65 years) with stage II/III GC who underwent curative laparoscopic D2 gastrectomy with R0 resection between 2004 and 2018. The adjuvant chemotherapy regimens included monotherapy (oral capecitabine) and doublet chemotherapy (oral capecitabine plus intravenous oxaliplatin [XELOX] or intravenous oxaliplatin, leucovorin, and 5-fluorouracil [FOLFOX]). The data were retrieved from a prospectively registered database maintained at the Department of General Surgery in Nanfang Hospital, China. The patients were divided as surgery alone and surgery plus adjuvant chemotherapy (chemo group). The overall survival (OS), disease-free survival (DFS), chemotherapy duration, and toxicity were examined.
\end{abstract}

Results: There were 270 patients included: 169 and 101 in the surgery and chemo groups, respectively. There were $10(10 / 101)$ and six (6/101) patients with grade $3+$ non-hematological and hematological adverse events. The 1-/3 - /5-year OS rates of the surgery group were 72.9\%/51.8\%/48.3\%, compared with 90.1\%/66.4\%/48.6\% for the chemo group (log-rank test: $P=0.018$ ). For stage III patients, the $1-/ 3-/ 5$-year OS rates of the surgery group were $83.7 \% /$ 40.7\%/28.7\%, compared with 89.9\%/61.2\%/43.6\% for the chemo group (log-rank test: $P=0.015$ ). Adjuvant chemotherapy was significantly associated with higher OS (HR=0.568, 95\%Cl: $0.357-0.903, P=0.017)$ and DFS $(\mathrm{HR}=0.511,95 \% \mathrm{Cl}: 0.322-0.811, P=0.004)$ in stage III patients.

(Continued on next page)

\footnotetext{
*Correspondence: liang.yanrui@qq.com

${ }^{\dagger}$ Yanrui Liang, Liying Zhao and Hao Chen contributed equally to this work. Department of General Surgery, Nanfang Hospital, Southern Medical University, 1838 North Guangzhou Ave, Guangzhou 510-515, China
}

(C) The Author(s). 2021 Open Access This article is licensed under a Creative Commons Attribution 4.0 International License, which permits use, sharing, adaptation, distribution and reproduction in any medium or format, as long as you give appropriate credit to the original author(s) and the source, provide a link to the Creative Commons licence, and indicate if changes were made. The images or other third party material in this article are included in the article's Creative Commons licence, unless indicated otherwise in a credit line to the material. If material is not included in the article's Creative Commons licence and your intended use is not permitted by statutory regulation or exceeds the permitted use, you will need to obtain permission directly from the copyright holder. To view a copy of this licence, visit http://creativecommons.org/licenses/by/4.0/. The Creative Commons Public Domain Dedication waiver (http://creativecommons.org/publicdomain/zero/1.0/) applies to the data made available in this article, unless otherwise stated in a credit line to the data. 
(Continued from previous page)

Conclusions: This study suggested that adjuvant chemotherapy significantly improves OS and DFS compared with surgery alone in elderly patients with stage III GC after D2 laparoscopic gastrectomy, with a tolerable adverse event profile.

Keywords: Gastric cancer, Gastrectomy, Adjuvant chemotherapy, Overall survival

\section{Background}

Gastric cancer (GC), as the fifth most frequently diagnosed cancer and the third leading cause of cancer death worldwide, was responsible for over 1,000,000 new cases and an estimated 783,000 deaths in 2018 [1]. The markedly elevated incidence rates of GC in Eastern Asia (China, Japan, and Korea) indicate that GC is a significant public health threat, especially to the elderly, since over $60 \%$ of the GC diagnoses and $70 \%$ of GC-related mortality occur in elderly patients (aged 65 years or older) $[2,3]$. As the population continues to age, the proportion of the population aged 60 years and over will increase from $12.4 \%$ in 2010 to $28 \%$ in 2040 [4]. Longer life expectancy also results in an increasing number of the elderly (aged 65 years or older) undergoing cancer operation and chemotherapy.

The survival benefits from gastrectomy plus chemotherapy have been confirmed in patients with advanced GC [5-7]. In the United States of America, chemoradiotherapy after gastrectomy has been confirmed to improve overall survival (OS) by the INT-0116 trial [8], while the progression-free survival (PFS) and OS benefits of perioperative chemotherapy have been shown by the MAGIC and FLOT4 trials [9, 10]. The adjuvant chemotherapy following D2 gastrectomy is a standard treatment for stage II/III GC in East Asia [11-13]. Although prior randomized controlled studies (RCTs) indicated that postoperative adjuvant treatment in patients who underwent D2 gastrectomy could improve the 5-year disease-free survival (DFS) and OS, the subgroup analyses showed that the survival benefits decreased with increasing age. Furthermore, the ACTSGC study showed no statistically significant effects of postoperative chemotherapy on DFS and OS for patients older than 70 years (DFS: hazard ratios $(\mathrm{HR})=$ 0.779, 95\% confidence interval (CI): 0.527-1.151; OS: $\mathrm{HR}=0.706,95 \% \mathrm{CI}:$ 0.490-1.017) [11]. Similar results for OS were observed in the CLASSIC study for patients older than 65 ( $\mathrm{HR}=0.70,95 \% \mathrm{CI}$ : 0.4-1.12) [12]. These results might be due to the considerably higher incidence of comorbidities, higher risk of complications, and shorter life expectancy of elderly patients [14]. Nevertheless, when considering those conflicting results, whether to give or not adjuvant chemotherapy to elderly patients with GC after D2 gastrectomy remains a dilemma for physicians. Therefore, the
International Society of Geriatric Oncology suggested that specific trials for older patients with cancer should be conducted [15].

Laparoscopic gastrectomy has gained popularity worldwide for its safety and effectiveness [16, 17]. The Chinese Laparoscopic Gastrointestinal Surgery (CLASS) group recently reported the primary endpoints of the CLASS-01 trial, which suggested that laparoscopic distal gastrectomy for advanced gastric cancer was non-inferior to open surgery in terms of 3-year DFS and safety, with significant minimally invasive benefits [18, 19]. A previous study by our group indicated the potential benefits of laparoscopic gastrectomy for elderly patients with resectable GC [20]. Ushimaru et al. [21] reported that laparoscopic gastrectomy might improve the OS by reducing mortality from respiratory diseases. Still, the benefit of adjuvant chemotherapy after laparoscopic D2 gastrectomy in elderly patients is unknown.

As the elderly patients (over 65 years of age) are underrepresented in most RCTs, the present study aimed to evaluate the effectiveness and complications of adjuvant chemotherapy retrospectively in elderly patients (over 65 years of age) after laparoscopic D2 gastrectomy, based on a prospectively registered database in China. Those results could help shed some light on this controversy.

\section{Methods \\ Study design and patients}

This was a retrospective cohort study conducted in the Department of General Surgery of Nanfang Hospital in patients treated between June 2004 and June 2018. This study was approved by the Ethics Committee of Nanfang Hospital. The need for written informed consent was waived due to the retrospective nature of this study.

The inclusion criteria were: 1 ) over 65 years of age; 2) histologically confirmed stage II or III gastric adenocarcinoma, according to American Joint Committee on Cancer (AJCC, 7th Edition); 3) received curative laparoscopic gastrectomy with D2 nodal dissection at Nanfang Hospital; and 4) at least 15 lymph nodes were available to ensure adequate disease classification. The exclusion criteria were: 1 ) residual tumors (R1/R2 resections or palliative surgery; 2) death within 1 month after surgery; 3) a previous history of primary or secondary tumor 
beside the current GC; 4) neoadjuvant chemotherapy or adjuvant radiotherapy; or 5) incomplete medical record .

The enrolled patients were divided into surgery alone group (surgery group) and the surgery plus adjuvant chemotherapy group (chemo group).

\section{Adjuvant chemotherapy protocols}

The adjuvant chemotherapy regimens administered during the study period included monotherapy and doublet chemotherapy. The initial dose of each regimen was reduced to $75 \%$ of the original value to minimize toxic effects in elderly patients. For monotherapy, the patients received 3-week cycles of oral capecitabine $\left(750 \mathrm{mg} / \mathrm{m}^{2}\right.$ twice daily on days 1 to 14 of each cycle) for 6 months if tolerated. For doublet chemotherapy, the patients received oral capecitabine plus intravenous oxaliplatin (XELOX) or 2-week cycles of intravenous oxaliplatin, leucovorin, and 5-fluorouracil (FOLFOX). For the XELOX regimen, patients received 3-week cycles of oral capecitabine $\left(750 \mathrm{mg} / \mathrm{m}^{2}\right.$ twice daily on days 1 to 14 of each cycle) plus intravenous oxaliplatin $\left(130 \mathrm{mg} / \mathrm{m}^{2}\right.$ on day 1 of each cycle) for 6 months if tolerated. The FOLFOX regimen was administered as follows: intravenous (IV) treatment with $63.75 \mathrm{mg} / \mathrm{m}^{2}$ of oxaliplatin, $300 \mathrm{mg} /$ $\mathrm{m}^{2}$ of leucovorin and IV push administration of $300 \mathrm{mg} /$ $\mathrm{m}^{2}$ of fluorouracil on day 1 , and $900 \mathrm{mg} / \mathrm{m}^{2}$ of fluorouracil IV by continuous infusion for $24 \mathrm{~h}$ on days 1 and 2 . This regimen was repeated every 14 days and lasted for 6 months if tolerated. In all regimens, the dose of each drug was reduced to the next lower dose increment in case of grade 4 neutropenia or thrombocytopenia, or grade 3 or above febrile neutropenia.

\section{Data collection}

The data were retrieved from a prospectively registered database maintained at the Department of General Surgery in Nanfang Hospital, China. The database includes patient characteristics (age at diagnosis, sex, etc.), clinical variables (postoperative stay, circulating tumor cells [CTCs] collected at postoperative two weeks, etc.), pathological features (tumor size, histological grade, etc.), chemotherapy (regimen, duration, cycles of chemotherapy, and grade 3 or above toxicity events), and follow-up. All data are routinely updated after each routine follow-up visit, either at the outpatient clinic or by phone. For the present study, the last follow-up data were collected on May 30th, 2018.

\section{Outcomes}

The observation outcomes of this study were OS and DFS. The OS was calculated from the date of operation to either the date of death or the date of the last followup visit. The DFS was calculated from the date of resection to the date of the first recurrence detected, or the last follow-up visit. Recurrence was determined as the appearance of any new lesion either locally, regionally, or distant. All grade 3 or above hematological and nonhematological toxicity events were recorded. Toxicities were graded according to the National Cancer Institute common toxicity criteria version 3.0 [22].

\section{Statistical analysis}

All statistical analyses were performed using SPSS 24.0 (IBM Corp., Armonk, NY, USA). Continuous variables were tested for normal distribution using the Kolmogorov-Smirnov test. Those with a normal distribution were expressed as means \pm standard deviations (SD) and were analyzed using Student's t-test; otherwise, they were presented as medians (ranges) and analyzed using the Mann-Whitney U-test. Categorical variables were reported as numbers with percentages and analyzed using the chi-square test with the Yates correction or Fisher's exact test, as appropriate. The OS and DFS rates were compared between the surgery and chemo groups using unadjusted Kaplan-Meier curves and the log-rank test. The OS and DFS rates of different clinicopathological characteristics and different chemotherapy regimen were compared. HR and $95 \%$ CI were used to estimate the role of each independent predictor of survival. The Cox regression model was used for univariable and multivariable analyses. We adjusted for the following variables: treatment regimens (with adjuvant chemotherapy or not), age of diagnosis, time of surgery, sex, ECOG score, Charlson score, tumor location, retrieved lymph node, hospital stays, AJCC stage, histologic grade, lymphatic, blood vessel or perineural invasion, tumor size, and CTC counts. Variables with $P<0.1$ in the univariable analysis were included in the multivariable analysis. The level of significance was set at a twotailed $P$-value of 0.05 .

\section{Results \\ Patient characteristics}

At first, 298 patients were eligible, but 28 were excluded because of the presence of residual tumors (R1/R2 resections and palliative surgery), death within 1 month of surgery, primary or secondary tumor history, neoadjuvant chemotherapy, adjuvant radiotherapy, or incomplete medical record. The remaining 270 patients were included in the analysis; 169 and 101 were classified in the surgery and chemo groups, respectively (Fig. 1).

Table 1 presents the characteristics of the patients. The median age in the surgery and chemo groups was 70 years (69-75 years) and 69 years (66-72 years), respectively $(P=0.001)$. The male-to-female ratio was 2.1 : 1 in the surgery group and 3.2:1 in the chemo group $(P=0.152)$. Most patients in the two groups had an 


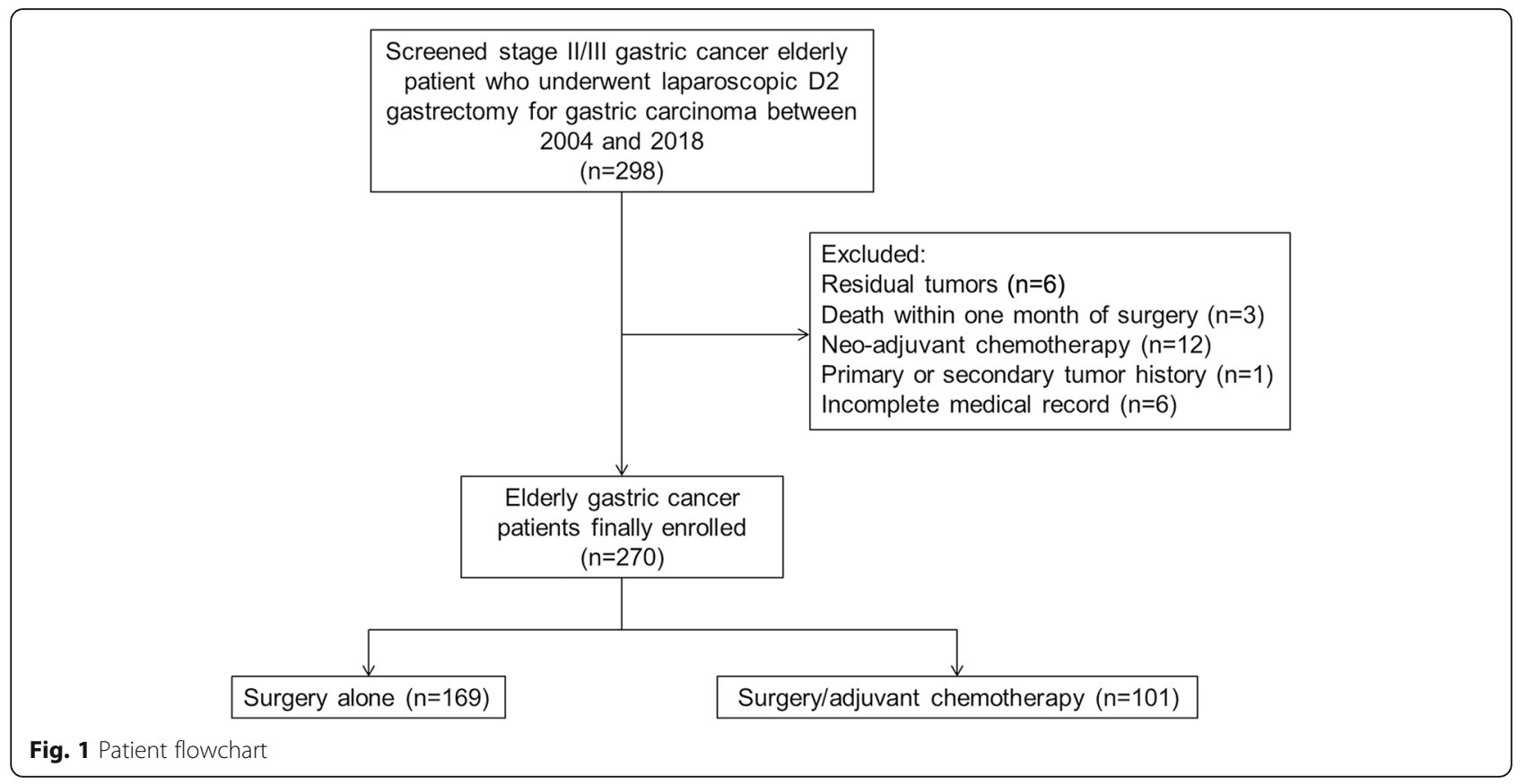

ECOG score and a Charlson comorbidity score of $\leq 1$ (ECOG: 88.2 and 89.1\%; Charlson score: 94.7 and 96.0\%; all $P>0.05)$. The number of CTCs in the surgery group was $5(2-16)$, while $4(1-7)$ in the chemo group $(P=$ 0.328 ). In the surgery group, there were 56 patients with AJCC stage II and 113 with AJCC stage III, while in the chemo group, there were 25 patients with AJCC stage II and 76 with AJCC stage III $(P=0.147)$. In the chemo group, six patients received monotherapy, and 95 patients received platinum-based doublet chemotherapy therapy; 57 patients received adjuvant chemotherapy for less than 3 months, while 44 patients received 3-6 months of adjuvant chemotherapy. The median followup in the surgery and chemo groups was 25 (IQR 1344) months, and 22 (IQR 11-54.5) months, respectively $(P=0.452)$.

\section{Factors associated with OS and DFS in all patients}

The univariable and multivariable Cox proportional hazards models for all patients are shown in Table 2 . In the multivariable analysis, age $>70$ years $(\mathrm{HR}=$ 1.640, 95\% CI: $1.119-2.403, P=0.011)$ and stage III GC $\quad(\mathrm{HR}=2.738,95 \%$ CI: $1.677-4.471, \quad P<0.001)$ were independently associated with OS. Surgery plus adjuvant chemotherapy ( $\mathrm{HR}=0.511$, 95\% CI: $0.322-$ $0.811, P=0.004)$, surgery performed in 2015-2018 (HR $=0.586,95 \%$ CI: 0.376-0.912, $P=0.018)$, and stage III GC $(\mathrm{HR}=2.345,95 \% \mathrm{CI}: 1.466-3.751, P<$ 0.001) were independently associated with DFS. Therefore, stage III GC was independently associated with both OS and DFS.

\section{Overall survival}

Unadjusted Kaplan-Meier survival curves were constructed for all patients in the two groups. The 1-, 3-, and 5-year OS rates of the surgery group were 72.9, 51.8 , and $48.3 \%$, compared with $90.1,66.4$, and $48.6 \%$ for the chemo group, respectively ( $\mathrm{HR}=0.61,95 \%$ CI: $0.42-$ $0.92, P=0.135$ ) (Fig. 2a). In the stage II cohort, the 1 -, 3 -, and 5-year OS rates of the surgery group were 96.3 , 80.4, and $72.7 \%$, compared with $90.5,73.8$, and $50.9 \%$ for the chemo group, respectively $(\mathrm{HR}=1.26,95 \% \mathrm{CI}$ : 0.483-3.29, $P=0.637$ ) (Fig. 2b). For stage III patients, the 1-, 3-, and 5-year OS rates of the surgery group were 83.7, 40.7, and $28.7 \%$, compared with $89.9,61.2$, and $43.6 \%$ for the chemo group, respectively ( $\mathrm{HR}=0.58,95 \%$ CI: $0.38-0.90, P=0.016$ ) (Fig. 2c).

\section{Disease-free survival}

The 1-, 3-, and 5-year DFS rates of the surgery group were $72.9,51.8$, and $48.4 \%$, compared with 81.3, 65.1, and $53.6 \%$ for the chemo group, respectively $(\mathrm{HR}=$ 0.682, 95\% CI: $0.463-1.005, P=0.053$ ) (Fig. $2 d$ ). In the stage II cohort, the 1-, 3-, and 5-year DFS rates of the surgery group were $85.3,78.5$, and $74.2 \%$, compared with $91.8,64.4$, and $64.4 \%$ for the chemo group, respectively $(\mathrm{HR}=1.02,95 \% \mathrm{CI}: 0.416-2.54, P=0.950$ (Fig. 2e). In stage III patients, the 1-, 3-, and 5-year DFS rates of the surgery group were $66.5,37.7$, and $34.8 \%$, compared with $77.9,60.0$, and $49.0 \%$ for the chemo group, respectively (HR $=0.55,95 \%$ CI: 0.36-0.83, $P=0.007$ ) (Fig. 2f). The OS and DFS in the stage III subgroup were significantly different between the surgery and Chemo groups. 
Table 1 Baseline information of patients

\begin{tabular}{|c|c|c|c|}
\hline Characteristics & Surgery $N=169$ & Chemotherapy $N=101$ & $p$ \\
\hline \multicolumn{4}{|l|}{ Clinical characteristics } \\
\hline Age at diagnosis (years), median (IQR) & $70(67-75)$ & $69(66-72)$ & 0.001 \\
\hline $65-70, n(\%)$ & $92(54.4)$ & $64(63.4)$ & 0.152 \\
\hline$>70, n(\%)$ & $77(45.6)$ & $40(39.6)$ & \\
\hline Time of surgery, $n(\%)$ & & & 0.684 \\
\hline $2005-2014$ & $81(47.9)$ & $51(50.5)$ & \\
\hline $2015-2018$ & $88(52.1)$ & $50(49.5)$ & \\
\hline Sex, $n(\%)$ & & & 0.152 \\
\hline Male & $115(68.0)$ & $77(76.2)$ & \\
\hline Female & $54(32.0)$ & $24(23.8)$ & \\
\hline ECOG score & & & 0.281 \\
\hline 0 & $78(46.2)$ & $54(63.5)$ & \\
\hline 1 & $71(42.0)$ & 36 (35.6) & \\
\hline 2 & $14(8.3)$ & $9(8.9)$ & \\
\hline $2+$ & $6(3.5)$ & $2(2.0)$ & \\
\hline Charlson score & & & 0.711 \\
\hline 0 & $128(75.7)$ & $74(73.3)$ & \\
\hline 1 & $32(18.9)$ & $23(22.8)$ & \\
\hline 2 & $8(4.8)$ & $3(2.9)$ & \\
\hline $2+$ & $1(0.6)$ & $1(1.0)$ & \\
\hline Tumour location & & & 0.524 \\
\hline Gastroesophageal junction & $58(34.3)$ & 39 (38.6) & \\
\hline Antrum & $88(52.1)$ & $49(48.5)$ & \\
\hline Other & $23(13.6)$ & $13(12.9)$ & \\
\hline Hospital stays (days), median (IQR) & $11(8-16)$ & $10.0(8-15)$ & 0.328 \\
\hline CTC (number), median (IQR) & $5(2-16)$ & $4(1-7)$ & 0.270 \\
\hline \multicolumn{4}{|l|}{ Pathological characteristics } \\
\hline TMN stage, $n(\%)$ & & & 0.147 \\
\hline$\|$ & $56(33.1)$ & $25(24.8)$ & \\
\hline III & $113(66.9)$ & $76(75.2)$ & \\
\hline T stage, $n(\%)$ & & & 0.286 \\
\hline $\mathrm{T} 1-2$ & $13(7.7)$ & $5(5.0)$ & \\
\hline T3 & $35(20.7)$ & $18(17.8)$ & \\
\hline T4 & $121(71.6)$ & $78(77.2)$ & \\
\hline N stage, $n(\%)$ & & & 0.285 \\
\hline No & $45(26.6)$ & $17(16.8)$ & \\
\hline N1 & $18(10.7)$ & $17(16.8)$ & \\
\hline N2 & $44(26.0)$ & $26(25.8)$ & \\
\hline N3 & $62(36.7)$ & $41(40.6)$ & \\
\hline Retrieved lymph nodes (number), median (IQR) & $40(25-55.5)$ & $38(24-54)$ & 0.516 \\
\hline Grade, $n(\%)$ & & & 0.051 \\
\hline Well or moderately differentiated & $123(72.8)$ & $84(83.2)$ & \\
\hline Poorly differentiated or undifferentiated & $46(27.2)$ & $17(16.8)$ & \\
\hline Lymphatic, blood vessel or perineural invasion, $n(\%)$ & $100(59.2)$ & $62(61.4)$ & 0.720 \\
\hline
\end{tabular}


Table 1 Baseline information of patients (Continued)

\begin{tabular}{lll}
\hline Characteristics & Surgery $\mathbf{N = 1 6 9}$ & Chemotherapy $\mathbf{N = 1 0 1}$ \\
\hline Tumour size (cm), mean \pm SD & $4.0(3.0-5.5)$ & $4.5(3.2-6.0)$ \\
$\leq 5 \mathrm{~cm}$ & $104(61.5)$ & $51(50.5)$ \\
$>5 \mathrm{~cm}$ & $65(38.5)$ & $50(49.5)$ \\
Drug delivery and toxicities & & \\
Adjuvant chemotherapy regimen & & 6.121 \\
$\quad$ Mono chemotherapy & & $95.9)$ \\
$\quad$ Doublet chemotherapy & & \\
Length of adjuvant chemotherapy & & $57(56.4)$ \\
$<3$ months & & $44(43.6)$ \\
3-6 months & & $1(1.0)$ \\
Toxicities (grade 3 or more) & $1(1.0)$ \\
Monotherapy & & 0 \\
Non-hematological adverse events & & $15(14.9)$ \\
Hematological adverse events & $9(8.9)$ \\
Double therapy & $6(5.9)$ \\
Non-hematological adverse events & & \\
Hematological adverse events & & \\
\hline
\end{tabular}

IQR interquartile range, ECOG Eastern Cooperative Oncology Group, CTC circulating tumor cells

\section{Subgroup survival analysis in stage III patients}

The univariable and multivariable Cox proportional hazards models in stage III patients are shown in Table 3. Surgery plus adjuvant chemotherapy $(\mathrm{HR}=0.568,95 \%$ CI: $0.357-0.903, P=0.017)$ and age $>70$ years $(\mathrm{HR}=$ 1.573, 95\% CI: $1.029-2.405, P=0.036)$ were independently associated with OS. Surgery plus adjuvant chemotherapy ( $\mathrm{HR}=0.511,95 \% \mathrm{CI}: 0.322-0.811, P=0.004)$ and surgery performed in $2015-2018, \mathrm{HR}=0.586,95 \%$ CI: $0.376-0.912, P=0.018)$ were independently associated with DFS.

\section{Chemotherapy regimens, duration, and toxicity}

In stage III patients, the platinum-based doublet chemotherapy led to better OS and DFS compared with monotherapy (OS: $P=0.037$; DFS: $P=0.013$ ) (Supplementary Fig. S2 A, C), but the differences were not statistically significant in stage II patients $(P=0.473$ and $P=0.499$ ) (Supplementary Fig. S1A, C). No significant differences in OS and DFS were observed in relation to chemotherapy duration (all $P>0.05$ ) (Supplementary Fig. S1 B,D; Supplementary Fig. S2 B, D). There were 10 patients with grade 3 or above non-hematological toxicity adverse events, and six with grade 3 hematological toxicity adverse events (neutropenia) (Table 1).

\section{Analysis in patients with available CTC data}

Forty-three patients had a CTC count before surgery, and 40 of them were positive. There were no significant differences in OS and DFS between the surgery and chemo groups among CTC-tested patients (Supplementary Fig. S3 A, C) and CTC-positive patients (all $P>$ 0.05) (Supplementary Fig. S3 B,D).

\section{Discussion}

The benefits of adjuvant chemotherapy for elderly patients (age over 65) with GC remain unknown because the elderly patients are underrepresented in most clinical trials [15]. Therefore this study aimed to evaluate the effectiveness and complications of adjuvant chemotherapy in elderly patients (over 65 years of age) after laparoscopic D2 gastrectomy. The results strongly suggest that adjuvant chemotherapy improves the OS and DFS of elderly patients with stage III GC operated using D2 laparoscopic gastrectomy compared with surgery alone.

Previously, there were a few single-center retrospective studies that focused on adjuvant chemotherapy for elderly patients after gastrectomy [23, 24]. Still, those previous studies might not represent the current status of advanced GC treatment since laparoscopic D2 gastrectomy became popular relatively recently [18]. In the present study, only elderly gastric patients who underwent laparoscopic D2 gastrectomy were included. Among them, 41\% received adjuvant chemotherapy in the $65-70$ age group and only $33 \%$ in the $>70$ age group. This finding is similar to other cancers $[25,26]$. This may be due to two reasons. First, there is no solid evidence to prove the efficacy of adjuvant chemotherapy in elderly patients with GC. Second, with a high 
Table 2 Association factors of OS and DFS in the total patients

\begin{tabular}{|c|c|c|c|c|c|c|c|c|}
\hline \multirow[b]{3}{*}{ Factors } & \multicolumn{4}{|l|}{ Overall survival } & \multicolumn{4}{|c|}{ Disease-free survival } \\
\hline & \multicolumn{2}{|c|}{ Univariable analysis } & \multicolumn{2}{|c|}{ Multivariable analysis } & \multicolumn{2}{|c|}{ Univariable analysis } & \multicolumn{2}{|c|}{ Multivariable analysis } \\
\hline & HR $(95 \% \mathrm{Cl})$ & $p$ & HR $(95 \% \mathrm{Cl})$ & $p$ & HR $(95 \% \mathrm{Cl})$ & $p$ & HR $(95 \% \mathrm{Cl})$ & $p$ \\
\hline \multicolumn{9}{|l|}{ Treatment } \\
\hline Surgery alone & 1 (Reference) & - & & & 1 (Reference) & - & 1 (Reference) & - \\
\hline Surgery/adjuvant chemotherapy & $\begin{array}{l}0.733(0.486- \\
1.106)\end{array}$ & 0.139 & & & $\begin{array}{l}0.673(0.447- \\
1.012)\end{array}$ & 0.057 & $\begin{array}{l}0.511(0.322- \\
0.811)\end{array}$ & 0.004 \\
\hline \multicolumn{9}{|l|}{ Age of diagnosis } \\
\hline $65-70$ years & 1 (Reference) & - & 1 (Reference) & - & 1 (Reference) & - & & \\
\hline$>70$ years & $\begin{array}{l}1.560(1.021- \\
2.385)\end{array}$ & 0.028 & $\begin{array}{l}1.640(1.119- \\
2.403)\end{array}$ & 0.011 & $\begin{array}{l}1.422(0.978- \\
2.067)\end{array}$ & 0.065 & & \\
\hline \multicolumn{9}{|l|}{ Time of surgery } \\
\hline 2004-2014 & 1 (Reference) & - & & & 1 (Reference) & - & 1 (Reference) & - \\
\hline 2015-2018 & $\begin{array}{l}0.967(0.632- \\
1.478)\end{array}$ & 0.876 & & & $\begin{array}{l}0.713(0.475- \\
1.069)\end{array}$ & 0.102 & $\begin{array}{l}0.586(0.376- \\
0.912)\end{array}$ & 0.018 \\
\hline \multicolumn{9}{|l|}{ Sex } \\
\hline Male & 1 (Reference) & - & & & 1 (Reference) & - & & \\
\hline Female & $\begin{array}{l}0.903(0.589- \\
1.383)\end{array}$ & 0.638 & & & $\begin{array}{l}0.895(0.588- \\
1.361)\end{array}$ & 0.603 & & \\
\hline \multicolumn{9}{|l|}{ ECOG score } \\
\hline 0 & 1 (Reference) & - & & & 1 (Reference) & - & & \\
\hline 1 & $\begin{array}{l}1.325(0.879- \\
1.996)\end{array}$ & 0.179 & & & $\begin{array}{l}1.468(0.982- \\
2.194)\end{array}$ & 0.062 & & \\
\hline 2 & $\begin{array}{l}1.006(0.504- \\
2.008)\end{array}$ & 0.987 & & & $\begin{array}{l}1.105(0.554- \\
2.202)\end{array}$ & 0.777 & & \\
\hline $2+$ & $\begin{array}{l}2.016(0.797- \\
5.100)\end{array}$ & 0.139 & & & $\begin{array}{l}2.017(0.798- \\
5.097)\end{array}$ & 0.138 & & \\
\hline \multicolumn{9}{|l|}{ Charlson score } \\
\hline 0 & 1 (Reference) & - & & & 1 (Reference) & - & & \\
\hline 1 & $\begin{array}{l}1.029(0.631- \\
1.679)\end{array}$ & 0.909 & & & $\begin{array}{l}1.068(0.661- \\
1.724)\end{array}$ & 0.788 & & \\
\hline 2 & $\begin{array}{l}0.992(0.363- \\
2.710)\end{array}$ & 0.988 & & & $\begin{array}{l}1.182(0.479- \\
2.961)\end{array}$ & 0.716 & & \\
\hline $2+$ & $\begin{array}{l}1.135(0.158- \\
8.174)\end{array}$ & 0.900 & & & $\begin{array}{l}1.368(0.190- \\
9.852)\end{array}$ & 0.756 & & \\
\hline \multicolumn{9}{|l|}{ Tumor location } \\
\hline Gastroesophageal junction & 1 (Reference) & - & & & 1 (Reference) & - & & \\
\hline Antrum & $\begin{array}{l}1.304(0.841- \\
2.023)\end{array}$ & 0.236 & & & $\begin{array}{l}1.321(0.861- \\
2.027)\end{array}$ & 0.203 & & \\
\hline Other & $\begin{array}{l}1.511(0.832- \\
2.724)\end{array}$ & 0.175 & & & $\begin{array}{l}1.497(0.840- \\
2.670)\end{array}$ & 0.171 & & \\
\hline Retrieved lymph node & $1.002(0.9931 .011)$ & 0.656 & & & $\begin{array}{l}0.999(0.990- \\
1.008)\end{array}$ & 0.841 & & \\
\hline Hospital stays & $\begin{array}{l}1.003(0.983- \\
1.023)\end{array}$ & 0.793 & & & $\begin{array}{l}1.006(0.987- \\
1.025)\end{array}$ & 0.550 & & \\
\hline \multicolumn{9}{|l|}{ AJCC stage } \\
\hline$\|$ & 1 (Reference) & - & 1 (Reference) & - & 1 (Reference) & - & 1 (Reference) & - \\
\hline III & $\begin{array}{l}2.626(1.610- \\
4.284)\end{array}$ & $\begin{array}{l}< \\
0.001\end{array}$ & $\begin{array}{l}2.738 \text { (1.677- } \\
4.471)\end{array}$ & $\begin{array}{l}< \\
0.001\end{array}$ & $\begin{array}{l}2.345(1.466- \\
3.751)\end{array}$ & $\begin{array}{l}< \\
0.001\end{array}$ & $\begin{array}{l}2.345(1.466- \\
3.751)\end{array}$ & $\begin{array}{l}< \\
0.001\end{array}$ \\
\hline
\end{tabular}


Table 2 Association factors of OS and DFS in the total patients (Continued)

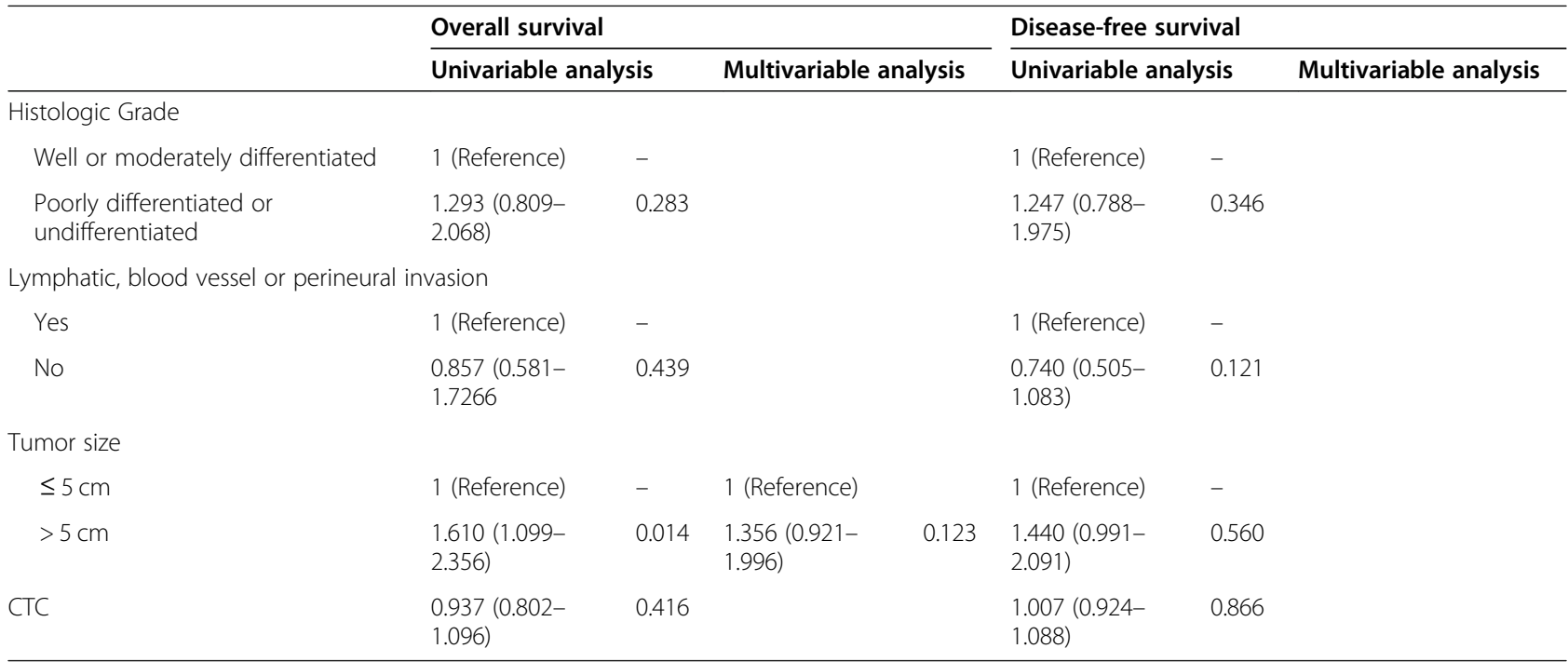

HR hazards ratio, Cl confidence interval, ECOG Eastern Cooperative Oncology Group, AJCC American Joint Cancer Committee, CTC circulating tumor cells We adjusted for the following variables: treatment regimens (with adjuvant chemotherapy or not), age of diagnosis, time of surgery, sex, ECOG score, Charlson score, tumor location, retrieved lymph node, hospital stays, AJCC stage, histologic grade, lymphatic, blood vessel or perineural invasion, tumor size, and CTC counts

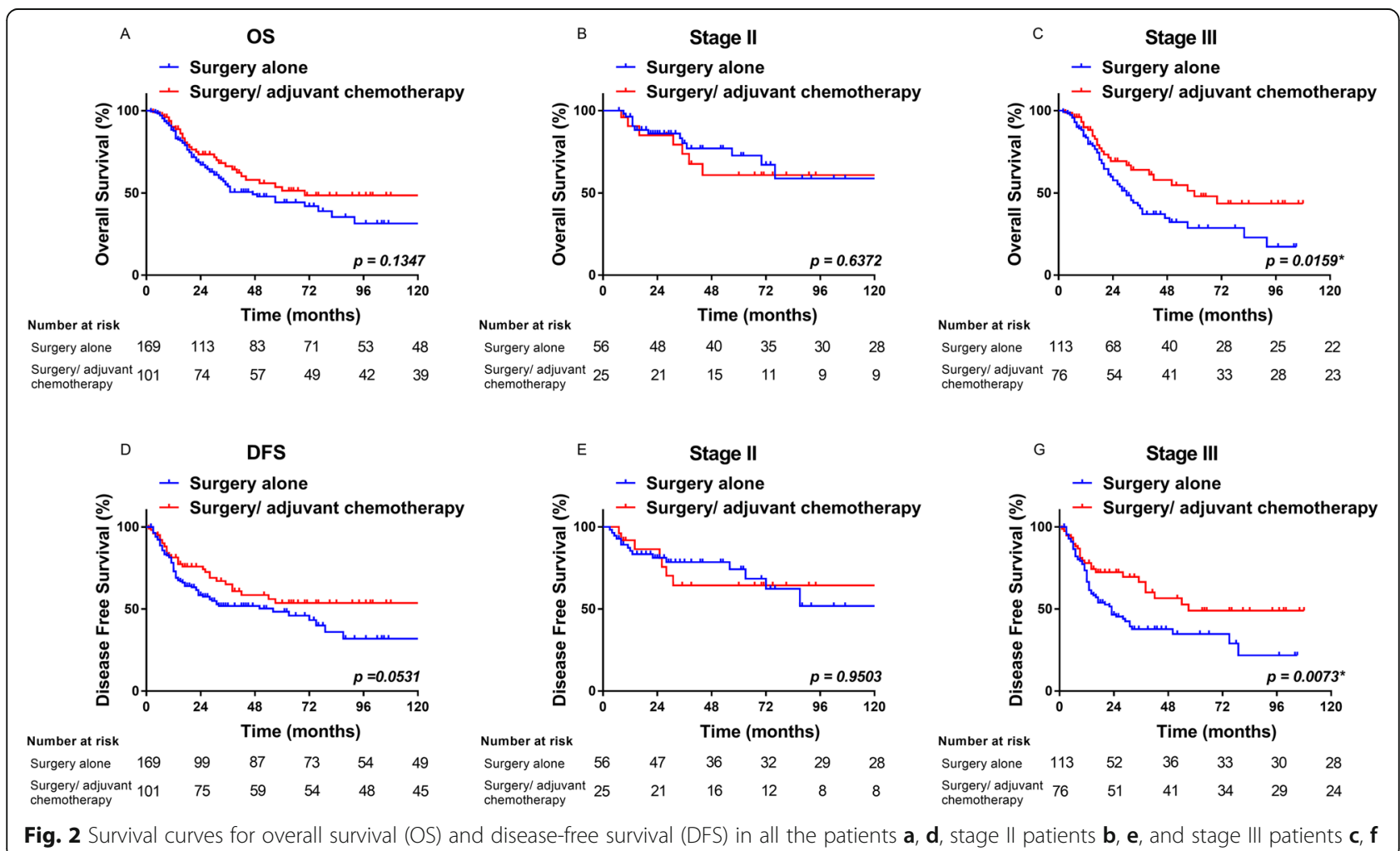


Table 3 Association factors of OS and DFS in stage III patients

\begin{tabular}{|c|c|c|c|c|c|c|c|c|}
\hline \multirow[b]{3}{*}{ Factors } & \multicolumn{4}{|c|}{ Overall survival } & \multicolumn{4}{|c|}{ Disease-free survival } \\
\hline & \multicolumn{2}{|c|}{ Univariable analysis } & \multicolumn{2}{|c|}{ Multivariable analysis } & \multicolumn{2}{|c|}{ Univariable analysis } & \multicolumn{2}{|c|}{ Multivariable analysis } \\
\hline & $\mathrm{HR}(95 \% \mathrm{Cl})$ & $p$ & $\mathrm{HR}(95 \% \mathrm{Cl})$ & $p$ & HR $(95 \% \mathrm{Cl})$ & $p$ & HR $(95 \% \mathrm{Cl})$ & $p$ \\
\hline \multicolumn{9}{|l|}{ Treatment } \\
\hline Surgery alone & 1 (Reference) & - & 1 (Reference) & - & 1 (Reference) & - & 1 (Reference) & - \\
\hline Surgery/adjuvant chemotherapy & $\begin{array}{l}0.572(0.360- \\
0.910)\end{array}$ & 0.018 & $\begin{array}{l}0.568(0.357- \\
0.903)\end{array}$ & 0.017 & $\begin{array}{l}0.542(0.342- \\
0.859)\end{array}$ & 0.009 & $\begin{array}{l}0.511(0.322- \\
0.811)\end{array}$ & 0.004 \\
\hline \multicolumn{9}{|l|}{ Age of diagnosis } \\
\hline $65-70$ years & 1 (Reference) & - & 1 (Reference) & - & 1 (Reference) & - & & \\
\hline$>70$ years & $\begin{array}{l}1.560(1.021- \\
2.385)\end{array}$ & 0.040 & $\begin{array}{l}1.573(1.029- \\
2.405)\end{array}$ & 0.036 & $\begin{array}{l}1.409(0.926- \\
1.943)\end{array}$ & 0.109 & & \\
\hline \multicolumn{9}{|l|}{ Time of surgery } \\
\hline 2004-2014 & 1 (Reference) & - & & & 1 (Reference) & - & 1 (Reference) & - \\
\hline 2015-2018 & $\begin{array}{l}0.895(0.565- \\
1.417)\end{array}$ & 0.636 & & & $\begin{array}{l}0.630(0.405- \\
0.980)\end{array}$ & 0.041 & $\begin{array}{l}0.586(0.376- \\
0.912)\end{array}$ & 0.018 \\
\hline \multicolumn{9}{|l|}{ Sex } \\
\hline Male & 1 (Reference) & - & & & 1 (Reference) & - & & \\
\hline Female & $\begin{array}{l}0.987 \text { (0.609- } \\
1.602)\end{array}$ & 0.959 & & & $0.957(0.591-1.55)$ & 0.860 & & \\
\hline \multicolumn{9}{|l|}{ ECOG score } \\
\hline 0 & 1 (Reference) & - & & & 1 (Reference) & - & & \\
\hline 1 & $\begin{array}{l}1.345(0.848- \\
2.132)\end{array}$ & 0.207 & - & - & $\begin{array}{l}1.493(0.948- \\
2.351)\end{array}$ & 0.083 & & \\
\hline 2 & $\begin{array}{l}1.201(0.576- \\
2.507)\end{array}$ & 0.625 & & & $\begin{array}{l}1.335(0.643- \\
2.773)\end{array}$ & 0.438 & & \\
\hline $2+$ & $\begin{array}{l}2.810(1.098- \\
7.188)\end{array}$ & 0.031 & & & $\begin{array}{l}2.715(1.061- \\
6.950)\end{array}$ & 0.037 & & \\
\hline \multicolumn{9}{|l|}{ Charlson score } \\
\hline 0 & 1 (Reference) & - & & & 1 (Reference) & - & & \\
\hline 1 & $\begin{array}{l}1.038(0.609- \\
1.771)\end{array}$ & 0.890 & & & $\begin{array}{l}1.119(0.664- \\
1.885)\end{array}$ & 0.674 & & \\
\hline 2 & $\begin{array}{l}1.000(0.364- \\
2.749)\end{array}$ & 0.999 & & & $\begin{array}{l}1.186(0.477- \\
2.946)\end{array}$ & 0.713 & & \\
\hline $2+$ & - & - & & & & & & \\
\hline \multicolumn{9}{|l|}{ Tumor location } \\
\hline Gastroesophageal junction & 1 (Reference) & - & & & 1 (Reference) & - & & \\
\hline Antrum & $\begin{array}{l}1.347(0.838- \\
2.166)\end{array}$ & 0.219 & & & $\begin{array}{l}1.368(0.858- \\
2.183)\end{array}$ & 0.188 & & \\
\hline Other & $\begin{array}{l}1.862(0.917- \\
3.780)\end{array}$ & 0.086 & & & $\begin{array}{l}1.521(0.753- \\
3.073)\end{array}$ & 0.242 & & \\
\hline Retrieved lymph node & $\begin{array}{l}1.001(0.991- \\
1.010)\end{array}$ & 0.853 & & & $\begin{array}{l}0.999(0.989- \\
1.009)\end{array}$ & 0.782 & & \\
\hline Hospital stays & $\begin{array}{l}1.001(0.980- \\
1.023)\end{array}$ & 0.905 & & & $\begin{array}{l}1.005(0.986- \\
1.025)\end{array}$ & 0.600 & & \\
\hline \multicolumn{9}{|l|}{ T stage } \\
\hline $\mathrm{T} 1-2$ & 1 (Reference) & - & & & 1 (Reference) & - & & \\
\hline T3 & $\begin{array}{l}0.596(0.130- \\
2.729)\end{array}$ & 0.505 & & & $\begin{array}{l}0.464(0.103- \\
2.098)\end{array}$ & 0.318 & & \\
\hline T4 & $\begin{array}{l}0.722(0.176- \\
2.958)\end{array}$ & 0.651 & & & $\begin{array}{l}0.576(0.141- \\
2.358)\end{array}$ & 0.443 & & \\
\hline
\end{tabular}


Table 3 Association factors of OS and DFS in stage III patients (Continued)

\begin{tabular}{|c|c|c|c|c|c|c|c|c|}
\hline \multirow[b]{3}{*}{ Factors } & \multicolumn{4}{|c|}{ Overall survival } & \multicolumn{4}{|c|}{ Disease-free survival } \\
\hline & \multicolumn{2}{|c|}{ Univariable analysis } & \multicolumn{2}{|c|}{ Multivariable analysis } & \multicolumn{2}{|c|}{ Univariable analysis } & \multicolumn{2}{|c|}{ Multivariable analysis } \\
\hline & $\mathrm{HR}(95 \% \mathrm{Cl})$ & $p$ & HR $(95 \% \mathrm{Cl})$ & $p$ & $\mathrm{HR}(95 \% \mathrm{Cl})$ & $p$ & HR $(95 \% \mathrm{Cl})$ & $p$ \\
\hline \multicolumn{9}{|l|}{ N stage } \\
\hline NO & 1 (Reference) & - & & & 1 (Reference) & - & & \\
\hline N1 & $\begin{array}{l}0.223(0.040- \\
1.231)\end{array}$ & 0.085 & & & $\begin{array}{l}0.234(0.042- \\
1.288)\end{array}$ & 0.095 & & \\
\hline N2 & $\begin{array}{l}0.517(0.121- \\
2.207)\end{array}$ & 0.373 & & & $\begin{array}{l}0.555(0.131- \\
2.357)\end{array}$ & 0.425 & & \\
\hline N3 & $\begin{array}{l}1.071(0.261- \\
4.398)\end{array}$ & 0.924 & & & $\begin{array}{l}1.065(0.259- \\
4.375)\end{array}$ & 0.930 & & \\
\hline \multicolumn{9}{|l|}{ Histologic Grade } \\
\hline Well or moderately differentiated & 1 (Reference) & - & & & 1 (Reference) & - & & \\
\hline $\begin{array}{l}\text { Poorly differentiated or } \\
\text { undifferentiated }\end{array}$ & $\begin{array}{l}1.035(0.609- \\
1.759)\end{array}$ & 0.899 & & & $\begin{array}{l}1.043(0.615- \\
1.769)\end{array}$ & 0.877 & & \\
\hline \multicolumn{9}{|c|}{ Lymphatic, blood vessel or perineural invasion } \\
\hline Yes & 1 (Reference) & - & & & 1 (Reference) & - & & \\
\hline No & $\begin{array}{l}0.899(0.581- \\
1.389)\end{array}$ & 0.631 & & & $\begin{array}{l}0.741(0.484- \\
1.134)\end{array}$ & 0.167 & & \\
\hline \multicolumn{9}{|l|}{ Tumor size } \\
\hline$\leq 5 \mathrm{~cm}$ & 1 (Reference) & - & & & 1 (Reference) & - & & \\
\hline$>5 \mathrm{~cm}$ & $\begin{array}{l}1.209(0.793- \\
1.843)\end{array}$ & 0.377 & & & $\begin{array}{l}1.147(0.756- \\
1.738)\end{array}$ & 0.519 & & \\
\hline
\end{tabular}

HR hazards ratio, Cl confidence interval, ECOG Eastern Cooperative Oncology Group, AJCC American Joint Cancer Committee

We adjusted for the following variables: treatment regimens (with adjuvant chemotherapy or not), age of diagnosis, time of surgery, sex, ECOG score, Charlson score, tumor location, retrieved lymph node, hospital stays, T stage, $\mathrm{N}$ stage, histologic grade, lymphatic, blood vessel or perineural invasion, and tumor size

comorbidity rate, older patients may prefer not to undergo chemotherapy treatment in their relatively limited lifetime [27].

Chemotherapy toxicity is another concern of the elderly who just underwent surgery. In the CLASSIC study, $56 \%$ of the patients who received the fluoropyrimidineplatinum chemotherapy regimen experienced grade 3-4 adverse events [12]. In the ACTS-GC study, $22.8 \%$ of patients with mono-chemotherapy experienced grade 3-4 adverse events [11]. In the present study, 95 (94.0\%) patients in the chemo group received platinum-based doublet chemotherapy, including XELOX and FOLFOX, and 15 (15.6\%) patients suffered from grade 3-4 adverse events. In the monotherapy group, one patient suffered from grade 3-4 non-hematological adverse events. The adverse event rate in our cohort is similar to a retrospective study from Korea [24]. Low rates of grade 3-4 adverse events may be due to the low Charlson comorbidity score in the present study since the patients were required to be able to tolerate laparoscopic D2 gastrectomy. The result indicates that adjuvant chemotherapy is tolerable in elderly patients who were suitable for gastrectomy. Still, it is possible that the adverse events were underestimated or not measured strictly in this retrospective study.
In the present study, adjuvant chemotherapy could significantly improve the OS in stage III elderly patients. Jin et al. [23] revealed an OS benefit $(P=$ 0.003 ) of adjuvant chemotherapy in elderly patients in a single-center retrospective study. A single-center retrospective study of elderly patients with GC (over 70 years $)$ in Korea reported a DFS benefit $(P=0.03)$ after adjuvant chemotherapy, but without an OS benefit $(P=0.242,24]$. Nevertheless, by analyzing elderly patients with resected GC in the SEERMedicare database, Hoffman et al. [28] reported that elderly patients might not gain a survival benefit from adjuvant chemotherapy, but most cases in this database underwent D0 or D1 gastrectomy. Up to now, no standard adjuvant chemotherapy regimens were established for the elderly. Some reports suggest that patients might benefit from adjuvant chemotherapy, no matter which chemotherapy regimen is used [29]. The CLASSIC study indicated that the fluoropyrimidine and oxaliplatin combination reduced both locoregional and distant recurrences, but had a smaller effect on peritoneal recurrences [12]. Kim et al. [30] reported that there were no significant improvements in OS and RFS when using longer treatments of fluoropyrimidine-based adjuvant 
chemotherapy in patients with stage II or III GC. Similar results were also observed in stage III colon cancer with 3 vs. 6 months of XELOX [31]. On the other hand, Feng et al. [32] reported that additional oral capecitabine for 6 months after eight cycles of XELOX improved the DFS and OS for stage IIIA GC. Still, those previous studies were not focused on elderly patients with GC. Elderly patients may prefer to undergo fewer treatments or treatments with fewer adverse effects in their relatively limited lifetime [27].

There are several limitations to this study. First, this study was based on retrospective data, with inherent shortcomings. For example, immortal time bias in the adjuvant group could not be completely avoided in a retrospective study. Secondly, it was a single center study, and it is unknown whether the results are valid externally. In addition, this was a strictly selected group of patients, excluding those with previous cancers, R1/2 resections and post-operative death. Consequently, the survival rates in both groups might not reflect realworld data. Finally, differences between the $<65$ and $\geq$ 65 year-old groups were not assessed. Further prospective studies are needed to address those issues.

\section{Conclusions}

In this retrospective, single-institution study, the OS and DFS benefited from adjuvant chemotherapy in elderly patients with stage III GC after D2 laparoscopic gastrectomy. Well-designed prospective studies are needed to confirm these findings. Elderly patients are highly variable in their functional status and comorbidities. Thus, cofactors regarding the functional, social, and mental status should also be considered. Further studies are needed to identify the elderly who can tolerate and benefit from adjuvant chemotherapy.

\section{Contribution to the field statement}

The benefits of adjuvant chemotherapy for elderly patients (age > 65) with gastric cancer (GC) remain unknown because elderly patients are underrepresented in most clinical trials. A total of 270 patients included for analysis. There were ten (10/101) and six (6/101) patients with grade $3+$ non-hematological and hematological adverse events. The 1-/3-/5-year OS rates of the surgery group were $72.9 \% / 51.8 \% / 48.3 \%$, compared with $90.1 \% / 66.4 \% / 48.6 \%$ for the chemo group (log-rank test: $P=0.018$ ). For stage III patients, the $1-/ 3$ -/5-year OS rates of the surgery group were $83.7 \%$ / $40.7 \% / 28.7 \%$, compared with $89.9 \% / 61.2 \% / 43.6 \%$ for the chemo group (log-rank test: $P=0.015$ ). Adjuvant chemotherapy was significantly associated with higher OS (HR $=0.568,95 \% \mathrm{CI}: 0.357-0.903, P=0.017)$ and DFS $(\mathrm{HR}=0.511,95 \% \mathrm{CI}: 0.322-0.811, P=0.004)$ in stage III patients. CTC $>0$ had no significant impact on the benefits of adjuvant chemotherapy on OS and DFS. These findings suggested that adjuvant chemotherapy significantly improves OS and DFS for elderly patients with stage III GC after D2 laparoscopic gastrectomy, with a tolerable adverse event profile.

\section{Supplementary Information}

The online version contains supplementary material available at https://doi. org/10.1186/s12885-021-07919-0.

Additional file 1: Supplementary Figure S1. Subgroup survival analysis for stage II patients in the chemotherapy group.

Additional file 2; Supplementary Figure S2. Subgroup survival analysis for stage III patients in the chemotherapy group.

Additional file 3: Supplementary Figure S3. Subgroup survival analysis in patients who had been tested for circulating tumor cells (CTCS) (A, C), and for those with positive CTCS (B, D).

\section{Abbreviations}

GC: Gastric cancer; OS: Overall survival; DFS: Disease-free survival; CTCs: Circulating tumor cells; PFS: Progression-free survival; RCTs: Randomized controlled studies; HR: Hazard ratios; Cl: Confidence interval; CLASS: The chinese laparoscopic gastrointestinal surgery; AJCC: American Joint Committee on Cancer; SD: Standard deviations

\section{Acknowledgments}

The authors would like to thank all study participants who were enrolled in this study.

\section{Authors' contributions}

YR L, LY Z and HC carried out the studies, participated in collecting data, and drafted the manuscript. TL, TC, ML Z, YF H and JY performed the statistical analysis and participated in its design. $H L$ and $G X L$ participated in acquisition, analysis, or interpretation of data and draft the manuscript. All authors read and approved the final manuscript.

\section{Funding}

The project was supported by grants from the State's Key Project of Research and Development Plan (2017YFC0108300), the National Natural Science Foundation of China (81672446), the Southern Medical University Clinical Research Start-Up Project (LC2016ZD003), and the Key Clinical Specialty Discipline Construction Program ([2012]121). The funding bodies had no rule in the design of the study and collection, analysis, and interpretation of data and in writing the manuscript.

\section{Availability of data and materials}

The datasets used and analysed during the current study are available from the corresponding author on reasonable request.

Ethics approval and consent to participate

This study was approved by the Ethics Committee of Nanfang Hospital. The need for written informed consent was waived due to the retrospective nature of this study.

Consent for publication

Not applicable.

Competing interests

All authors declare no conflict of interest associated with this manuscript. 
Received: 12 August 2020 Accepted: 16 February 2021

Published online: 25 February 2021

\section{References}

1. Bray F, Ferlay J, Soerjomataram I, Siegel RL, Torre LA, Jemal A. Global cancer statistics 2018: GLOBOCAN estimates of incidence and mortality worldwide for 36 cancers in 185 countries. CA Cancer J Clin. 2018;68:394-424.

2. Yancik R, Ries LA. Cancer in older persons. Magnitude of the problem--how do we apply what we know? Cancer. 1994;74:1995-2003.

3. Joharatnam-Hogan N, Shiu KK, Khan K. Challenges in the treatment of gastric cancer in the older patient. Cancer Treat Rev. 2020;85:101980.

4. WHO. China country assessment report on ageing and health. . https:// wwww.hoint/ageing/publications/china-country-assessment/en/. 2015.

5. Hu JK, Chen ZX, Zhou ZG, Zhang B, Tian J, Chen JP, Wang L, Wang CH, Chen HY, Li YP. Intravenous chemotherapy for resected gastric cancer: meta-analysis of randomized controlled trials. World J Gastroenterol. 2002;8: 1023-8.

6. Wu DM, Wang S, Wen X, Han XR, Wang YJ, Shen M, Fan SH, Zhang ZF, Zhuang J, Shan Q, et al. Survival Benefit of Three Different Therapies in Postoperative Patients With Advanced Gastric Cancer: A Network MetaAnalysis. Front Pharmacol. 2018;9:929.

7. NCCN. Clinical Prtactice guidelines in Oncolofy (NCCN guidelines). Gastric Cancer. Fort Washington: National Comprehensive Cancer Network; 2020.

8. Macdonald JS, Smalley SR, Benedetti J, Hundahl SA, Estes NC, Stemmermann GN, Haller DG, Ajani JA, Gunderson LL, Jessup JM, et al. Chemoradiotherapy after surgery compared with surgery alone for adenocarcinoma of the stomach or gastroesophageal junction. N Engl J Med. 2001;345:725-30.

9. Cunningham D, Allum WH, Stenning SP, Thompson JN, Van de Velde CJ, Nicolson M, Scarffe JH, Lofts FJ, Falk SJ, Iveson TJ, et al. Perioperative chemotherapy versus surgery alone for resectable gastroesophageal cancer. N Engl J Med. 2006;355:11-20.

10. Al-Batran SE, Homann N, Pauligk C, Goetze TO, Meiler J, Kasper S, Kopp HG, Mayer F, Haag GM, Luley K, et al. Perioperative chemotherapy with fluorouracil plus leucovorin, oxaliplatin, and docetaxel versus fluorouracil or capecitabine plus cisplatin and epirubicin for locally advanced, resectable gastric or gastro-oesophageal junction adenocarcinoma (FLOT4): a randomised, phase 2/3 trial. Lancet (London, England). 2019;393:1948-57.

11. Sasako M, Sakuramoto S, Katai H, Kinoshita T, Furukawa H, Yamaguchi T, Nashimoto A, Fujii M, Nakajima T, Ohashi Y. Five-year outcomes of a randomized phase III trial comparing adjuvant chemotherapy with S-1 versus surgery alone in stage II or III gastric cancer. J Clin Oncol. 2011;29: 4387-93.

12. Noh SH, Park SR, Yang HK, Chung HC, Chung IJ, Kim SW, Kim HH, Choi JH, Kim HK, Yu W, et al. Adjuvant capecitabine plus oxaliplatin for gastric cancer after D2 gastrectomy (CLASSIC): 5-year follow-up of an open-label, randomised phase 3 trial. Lancet Oncol. 2014;15:1389-96.

13. Yoshida K, Kodera Y, Kochi M, Ichikawa W, Kakeji Y, Sano T, Nagao N, Takahashi M, Takagane A, Watanabe T, et al. Addition of Docetaxel to Oral Fluoropyrimidine improves efficacy in patients with stage III gastric Cancer: interim analysis of JACCRO GC-07, a randomized controlled trial. J Clin Oncol. 2019;37:1296-304.

14. Saif MW, Makrilia N, Zalonis A, Merikas M, Syrigos K. Gastric cancer in the elderly: an overview. Eur J Surg Oncol. 2010;36:709-17.

15. Wildiers H, Mauer M, Pallis A, Hurria A, Mohile SG, Luciani A, Curigliano G, Extermann M, Lichtman SM, Ballman K, et al. End points and trial design in geriatric oncology research: a joint European organisation for research and treatment of cancer--Alliance for clinical trials in oncology--international society of geriatric oncology position article. J Clin Oncol. 2013;31:3711-8.

16. Wei Y, Yu D, Li Y, Fan C, Li G. Laparoscopic versus open gastrectomy for advanced gastric cancer: a meta-analysis based on high-quality retrospective studies and clinical randomized trials. Clin Res Hepatol Gastroenterol. 2018;42:577-90.

17. Beyer K, Baukloh AK, Kamphues C, Seeliger H, Heidecke CD, Kreis ME, Patrzyk M. Laparoscopic versus open gastrectomy for locally advanced gastric cancer: a systematic review and meta-analysis of randomized controlled studies. World J Surg Oncol. 2019;17:68.

18. Yu J, Huang C, Sun Y, Su X, Cao H, Hu J, Wang K, Suo J, Tao K, He X, et al. Effect of laparoscopic vs open distal Gastrectomy on 3-year disease-free survival in patients with locally advanced gastric Cancer: the CLASS-01 randomized clinical trial. JAMA. 2019;321:1983-92.
19. Hu Y, Huang C, Sun Y, Su X, Cao H, Hu J, Xue Y, Suo J, Tao K, He X, et al. Morbidity and mortality of laparoscopic versus open D2 distal Gastrectomy for advanced gastric Cancer: a randomized controlled trial. J Clin Oncol. 2016;34:1350-7.

20. Yu J, Hu J, Huang C, Ying M, Peng X, Wei H, Jiang Z, Du X, Liu Z, Liu H, et al. The impact of age and comorbidity on postoperative complications in patients with advanced gastric cancer after laparoscopic D2 gastrectomy: results from the Chinese laparoscropic gastrointestinal surgery study (CLAS S) group. Eur J Surg Oncol. 2013;39:1144-9.

21. Ushimaru Y, Kurokawa Y, Takahashi T, Saito T, Yamashita K, Tanaka K, Makino T, Yamasaki M, Nakajima K, Mori M, et al. Is laparoscopic Gastrectomy more advantageous for elderly patients than for young patients with Resectable advanced gastric Cancer? World J Surg. 2020;44:2332-9.

22. Trotti A, Colevas AD, Setser A, Rusch V, Jaques D, Budach V, Langer C, Murphy B, Cumberlin R, Coleman CN, et al. CTCAE v3.0: development of a comprehensive grading system for the adverse effects of cancer treatment. Semin Radiat Oncol. 2003;13:176-81.

23. Jin Y, Qiu MZ, Wang DS, Zhang DS, Ren C, Bai L, Luo HY, Wang ZQ, Wang FH, Li YH, et al. Adjuvant chemotherapy for elderly patients with gastric cancer after D2 gastrectomy. PLoS One. 2013;8:e53149.

24. Jo JC, Baek JH, Koh SJ, Kim H, Min YJ, Lee BU, Kim BG, Jeong ID, Cho HR, Kim GY. Adjuvant chemotherapy for elderly patients (aged 70 or older) with gastric cancer after a gastrectomy with D2 dissection: a single center experience in Korea. Asia-Pac J Clin Oncol. 2015;11:282-7.

25. Merchant SJ, Nanji S, Brennan K, Karim S, Patel SV, Biagi JJ, Booth CM. Management of stage III colon cancer in the elderly: practice patterns and outcomes in the general population. Cancer. 2017;123:2840-9.

26. Samet J, Hunt WC, Key C, Humble CG, Goodwin JS. Choice of cancer therapy varies with age of patient. JAMA. 1986;255:3385-90.

27. Dudeja V, Habermann EB, Zhong W, Tuttle TM, Vickers SM, Jensen EH, AlRefaie WB. Guideline recommended gastric cancer care in the elderly: insights into the applicability of cancer trials to real world. Ann Surg Oncol. 2011;18:26-33.

28. Hoffman KE, Neville BA, Mamon HJ, Kachnic LA, Katz MS, Earle CC, Punglia RS. Adjuvant therapy for elderly patients with resected gastric adenocarcinoma: population-based practices and treatment effectiveness. Cancer. 2012;118:248-57.

29. Liu TS, Wang Y, Chen SY, Sun YH. An updated meta-analysis of adjuvant chemotherapy after curative resection for gastric cancer. Eur J Surg Oncol. 2008;34:1208-16.

30. Kim SG, Hwang SH. The association between the duration of fluoropyrimidine-based adjuvant chemotherapy and survival in stage II or III gastric cancer. World J Surg Oncol. 2016;14:102.

31. Grothey A, Sobrero AF, Shields AF, Yoshino T, Paul J, Taieb J, Souglakos J, Shi Q, Kerr R, Labianca R, et al. Duration of adjuvant chemotherapy for stage III Colon Cancer. N Engl J Med. 2018;378:1177-88.

32. Feng WM, Tang CW, Guo HH, Bao Y, Fei MY. Prolonged adjuvant capecitabine chemotherapy improved survival of stage IIIA gastric cancer after D2 gastrectomy. Biomed Pharmacother. 2015;72:140-3.

\section{Publisher's Note}

Springer Nature remains neutral with regard to jurisdictional claims in published maps and institutional affiliations.

\section{Ready to submit your research? Choose BMC and benefit from:}

- fast, convenient online submission

- thorough peer review by experienced researchers in your field

- rapid publication on acceptance

- support for research data, including large and complex data types

- gold Open Access which fosters wider collaboration and increased citations

- maximum visibility for your research: over $100 \mathrm{M}$ website views per year

At BMC, research is always in progress.

Learn more biomedcentral.com/submissions 